\title{
Narratives in practice
}

\section{Hinton, L Locock, S Ziebland Health Experiences Research Group, Nuffield Department of Primary Care Health Sciences, University of Oxford \\ Title: Understanding and using health experiences to improve healthcare - UK examples}

This chapter explores the variety of ways in which people's narrative accounts of their health experiences can be harnessed to inform practice, service development and health policy as well as a more traditional research agenda. Collecting data on patient experience as an activity in isolation is not enough. There is a strong case for health experiences to be used to improve care (Ziebland, 2013). In this chapter, we present examples of projects conducted in the United Kingdom where we have used patient narratives collected as part of the Healthtalk project (www.healthtalk.org) for health service improvement.

\section{How do we know what matters to patients?}

The endeavour of collecting and understanding patient experiences has expanded and matured in recent years. Patient experiences can be gathered through many routes; unsolicited sources, such as complaints direct to hospitals and also a wide variety of research and audit methods including questionnaire surveys (either national, local, or hospital specific), in video feedback kiosks in hospitals where patients can leave feedback messages, in focus groups (run face to face or online), and in research interviews in various forms (structured, semi-structured or narrative). These sources are varied in the kinds of data they can give, and in the Internet age, they are diversifying rapidly. Similarly, we can capture what matters to patients through a range of sources such as ratings websites (e.g. Patient Opinion, or service specific ones) as well as less direct sources such as YouTube videos, Twitter, social media sites, personal blogs and online patient forums.

\section{Box 1}

Examples of online sources of patients' views
1) Patient Opinion
2) You Tube video channel for patient feedback
3) Twitter handles
4) Social media
5) Blogs/vlogs
6) Patient forums

There are strengths and limitations to all sources of patient experience data. The detail (richness) of the experience is to a large degree dependent on the source - a narrative interview will potentially give richer insights into a patient's experiences of health care (an outpatient hospital appointment, inpatient care) than responses given to a patient satisfaction questionnaire. The insights from an interview may also 
uncover unanticipated details of care that would be glossed over by patients in questionnaire responses that are often overly positive (Ziebland S, 2011). But conversely, constrained by time and money, researchers may be able to collect questionnaire responses from hundreds of patients, but narrative interviews with only a few.

The Health Experiences Research Group (HERG) in the University of Oxford's Nuffield Department of Primary Care Health Sciences has conducted over 100 narrative studies of health experiences since 1999 that form an archive of interviews with more than 4,000 patients. Since 2001 analytic summaries of key themes in these patient experiences, illustrated with video and audio excerpts from the interviews, have been published on the website Healthtalk.org, (formerly known as DIPEx and Healthtalkonline) designed as a resource for patients, relatives and carers, the general public, policy makers, health professionals in practice and training. HERG researchers have also published over 180 peer-reviewed papers in clinical and social science journals and the interview archive has been used for numerous secondary analyses, reports and papers.

\section{The value of narrative}

Narratives engage hearts as well as minds, conveying a message "under the radar" and by-passing rational objections. Psychological approaches, such as transportation theory and the concept of narrative persuasion (Cin, 2004, Green, 2000), suggest that narratives are a credible, powerful and persuasive way of accessing human experience, transporting us directly into another's perspective. This can encourage care providers to rethink attitudes and motivate them to reflect on how services could be improved (Greenhalgh, 2005, Bate, 2007). Authors in JAMA argued that "although narrative is often maligned as anecdote and thus scrubbed from the toolbox of guideline developers, epidemiologists and regulatory scientists, these experts should consider narrative to develop and translate evidence-based policies."(Zachary, 2011)

BOX 2 Examples of where a secondary analysis of illness narratives, originally collected for use on the Healthtalk.org website and now stored in the Health Experiences Research Group (HERG) archive, has been used. Each study here has used transcripts of interviews previously collected for other projects for a reanalysis to inform new research studies.

- Information for Choice' project included secondary analysis of five collections from the HERG archive (Hunt, France and Wyke et al 2009)

- Identifying item pools for questionnaire development e.g. e-Health Impact Questionnaire (Kelly, Jenkinson and Ziebland 2013)

- Analysis of 80+ narrative interviews to inform General Medical Council 'end of life' guidelines for doctors (GMC 2010)

- Redesigning the medical curriculum on autism for family doctors (Soar, Ryan and Salisbury 2014) 
- Gathering treatment uncertainties from patient/carers using different methods: evaluation report for the Oxford Biomedical Research Centre with the James Lind Alliance Hip and Knee Replacement for Osteoarthritis Priority Setting Partnership (Crowe and Regan 2014)

- Service improvement 'trigger films' for co-design workshops (Locock et al 2014)

- Informing NICE Guideline and Quality standards (Ziebland et al 2014)

\section{Secondary analysis}

Patient experiences can inform health policy across areas wider than the single health conditions. These activities can take place as part of the primary research project, or through secondary analysis projects (Heaton 2004). One example was a study funded by the National Institute of Health Research (NIHR) in 2014 to use a secondary analysis of a purposive sample of HERG narrative interviews (on experiences of autism, rheumatoid arthritis, cancer and infertility) to identify core components of what 'good healthcare' looks like. Initial analyses were tested in focus groups with hard to reach populations (e.g. travelers, migrant workers, people with a long-term condition). A scientific summary was published in the NIHR publications library and illustrative clips were included on Healthtalk.org (Ziebland et al 2014).

\section{What does good healthcare look like to patients?}

1. Having a friendly and caring attitude

2. Having some understanding of how my life is affected

3. Letting me see the same health professional

4. Guiding me through difficult conversations

5. Taking time to answer my questions and explain things well

6. Pointing me towards further support

7. Efficient sharing of my health information across services

8. Involving me in decisions about my care

\section{Service improvement 'trigger films' for experience based co-design}

Another avenue for making use of patient narratives for service improvement is through an approach called experience-based co-design (EBCD), a participatory action research approach in which patients and staff work together to improve quality. In its pure form (Bate and Robert 2007, The King's Fund toolkit) it is based on narratives collected via local interviews with patients and staff about their experiences of a particular service (the discovery phase). Interviews with patients are recorded on video, and short trigger films of their experiences are produced to show to staff and patients working together as equal partners. Agreed priorities for change are taken forward to staff and patient/carer groups to plan and implement improvements together (the co-design phase). Evaluations suggest that this approach is highly effective (Piper et al 2012, Donetto, Pierri, Tsianakas and Robert 2015) but time and resource intensive. This led to a project testing whether the national narrative studies in the HERG/Healthtalk archive could be used to contribute to service improvement. 


\section{'Accelerated' experience based co-design (AEBCD)}

In this accelerated form of EBCD, trigger films on lung cancer and intensive care were produced from a secondary analysis of the HERG archive instead of conducting local interviews in the discovery phase. These were used in two trusts as the first step in the process, enabling the trusts to move swiftly to the co-design phase. Both staff and patients engaged positively with the material, and similar results to a traditional EBCD project were achieved (Locock et al 2014) ${ }^{1}$. Importantly this study demonstrated that existing narrative data could be re-used to stimulate change across multiple sites, without the need to repeat interviews in each new location.

Having demonstrated proof of concept in this initial study, the same material from Healthtalk has been further re-used in the SILENCE study aimed at lowering elements of noise in the critical care environment ${ }^{2}$. The intensive care unit (ICU) is a specialist hospital ward where the most critically ill or unstable patients are cared for. A patient in ICU usually has one to one nursing care, as they require constant medical attention and support to keep their body functioning. They may be unable to breathe and have multiple organ failure. Patients are often sedated or unconscious. The units tend to be small, highly technical environments with several monitors at each bedside. They are also noisy. Although the World Health Organisation (WHO) recommends that the average hospital sound levels should not exceed an average of $35 \mathrm{dBA}$ with peak sounds no lounder than 40dBA

(Berglund BL, Schwela 1999). But in reality a typical ICU is about as loud as a busy restaurant or the traffic on a main road (around 60dB) (Darbyshire and Young 2013). This cacophony of unfamiliar noises can be terrifying to vulnerable patients, and high background noise is likely to contribute to abnormal sleep, and ICU-acquired delirium which can in turn lead to longer hospital stays and more health problems after discharge (Darbyshire et al 2016).

The overall aim of the SILENCE study was to design an intervention to reduce noise levels in the ICU. In addition to technical changes, a practical behaviour change was attempted, informed by patient narratives ${ }^{3}$. In the summer 2015 a joint staff and

\footnotetext{
${ }^{1}$ The project, Testing accelerated experience-based co-design: a qualitative study of using a national archive of patient experience narrative interviews to promote rapid patient-centred service improvement, was funded by the National Institute of Health Research (NIHR) Health Service \&Delivery Research (HS\&DR) scheme (10/1009/14). The views expressed are those of the authors and not necessarily those of the NHS, the NIHR or the Department of Health.

2 The project, Sleep in the Intensive Care Unit: lowering elements of noise in the critical care environment (SILENCE), was funded by the NIHR Research for Patient Benefit (RfPB) scheme (PB-PG-0613-31034). The views expressed are those of the authors and not necessarily those of the NHS, the NIHR or the Department of Health. ${ }^{3}$ http://www.healthtalk.org/peoples-experiences/intensive-care/intensive-carepatients-experiences/topics. Module funded by Intensive Care National Audit and Research Centre (ICNARC)
} 
patient workshop used the AEBCD framework (described above) and showed trigger films produced from the narratives of patient and relative experiences of ICU in the HERG archive. Sixteen people, including three patients, two patient advocates, ICU nurses, doctors and a manager, were shown trigger films themed around 'alarms', 'lights', 'being disturbed by equipment', 'being disturbed by people', 'feeling overwhelmed'. The group agreed a cohesive package of changes required to enable the ICU to become 'quiet'.

\section{Developing training materials based on patient narratives}

Individuals prefer to learn in different ways. This must be accounted for when designing an educational intervention to ensure that all learners have a productive experience. Honey and Mumford et al (1986) describe four stereotypes. These are reflectors (those who when provided with new information prefer to consider this thoroughly before acting), activists (who prefer to learn by experimentation), theorists (integrate information into a coherent and rational scheme), and pragmatists (keen to receive concepts directly applicable to them and less interested in abstract theory).

Taking account of this variation, the findings from the secondary analysis of narratives and the AEBCD event were used to inform the development of a teaching package for ICU staff in a UK hospital. This was designed to raise awareness of the effect high noise levels can have on the patient experience of intensive care and had something to offer for all learning styles. It incorporated an e-learning module that included information presented in a variety of formats, and self-assessment questionnaires. It also included an experiential aspect, a critical part of the adult learning processes. Adults learn very differently from children and are motivated by perceived personal need. Kolb et al (1975) describes a cycle by which adults reflect upon experiences and adapt their behaviours based on this reflection. Therefore experiential learning is a powerful tool in adult education.

During the experiential session staff were asked to lie on a hospital bed, as if a patient. They were played simulated ICU sounds, given poor vision (with an eye mask) and subjected to 'live activities' going on around them. This live action was based on activities witnessed during ethnographic observation sessions undertaken earlier in the SILENCE project and included having their blood pressure and oxygen saturation measured (with altered alerting parameters to induce an unexpected alarm), drawers and doors being opened, apron rollers spinning, bin lids crashing and trolleys being pushed by.

An assessment tool was also designed to test knowledge and attitudes post-training. Nurses, doctors and physiotherapists took part. When asked to describe the immersive experience staff identified words such as 'uncomfortable', 'watched', 'alone', 'frightening', 'confused' and 'worrying'. Staff found the experience useful and felt it re-created the patient experience well. They described various changes to their own practice including reassuring patients and reducing noise through lowering verbal volume and attending to equipment noise and alarms more swiftly. The combination of environmental changes and awareness teaching successfully reduced 
noise levels by about $4 \mathrm{~dB}$ with before and after median (inter quartile range) $24 \mathrm{hr}$ levels of 57.0 (3.2) and 53.2 (5.1) respectively. Sound level 'signatures' were also altered after the intervention suggesting that a reduction in peak values may be the 'driver' for the change ${ }^{4}$.

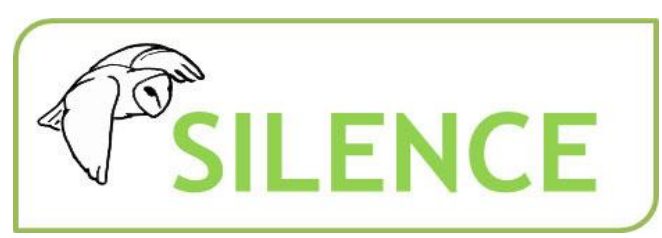

Oxford University Hospitals WHS NHS Trust

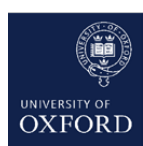

The National Institute for Health Research funds the SILENCE research project at the University of Oxford and Oxford University Hospitals NHS Trust.

Improving patient experience is a priority for the government and the NHS - and for all of us who use the NHS. But to do this we need to understand better what it is really like to be a patient with a particular condition, and patients need a direct say in planning changes to health care that make a real difference to them.'

One approach that has been used successfully in other hospitals is a process called accelerated experience-based co-design (also called AEBCD).

In $A E B C D$, short films of patient interviews are shown to a mixed group of staff and patients to start discussion and 'co-design' work between patients and staff to improve hospital services.

Using clips from patient interviews recorded by researchers from the University of Oxford, we are creating a film where patients talk about noise in the intensive care unit. Early in the summer we will bring together staff and patients from the local NHS Trust to discuss ways to lower noise levels in the ICU to make it a quieter, more restful place to recover from illness. We expect this discussion to last about half a day, and we will provide lunch and other refreshments.

After the discussion session we would like people to meet again in smaller groups to develop noise reduction plans which will be introduced into the ICU in October.

We will measure noise levels before and after the changes are introduced.

Finally we would like to invite everyone from the co-design group to an end of project event where we will share the results.

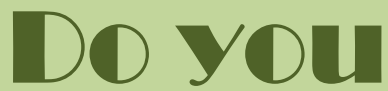

think it is too noisy in the CU?

What effect do you think this has on patients?

Can you help us make it quieter?

We are looking for ICU patients and their families to help design noise reduction plans which will be introduced into the intensive care unit later this year.

Locock L, Robert G, Boaz A, Vougioukalou S, Shuldham C, Fielden J, et al. Testing accelerated experience-based co-design: a qualitative study of using a national archive of patient experience narrative interviews to promote rapid 


\section{Potential drawbacks to using health narratives to guide health care improvements}

Patients' narratives about their experiences can be powerful, invoking a strong emotional response from those who engage with them. They can also be memorable, shaping staff practices in subtle as well as overt ways. These characteristics mean that they have the potential to do harm as well as good, especially if the members of staff close ranks defensively, or suspect that the narratives have been chosen to criticise practice or reflect minority interests. Any improvement work may divert staff from usual patient care, adding strain to the delivery of the service - it is therefore imperative that the narratives are chosen carefully, that they provide balanced reflections on care and (as far as can be ascertained) do not serve as a vehicle for vested interests.

Patients' narratives are nowadays also freely available online, through blogs and social media as well as feedback sites. To date there has been little examination of the individual and organisational responses to the use of online feedback in the NHS. We know that the diffusion of innovations in healthcare, especially information technology-based innovation, is complex and influenced by multiple individual and organisational factors. For example, many clinicians appear resistant to the idea of online feedback, worrying about selection bias, vulnerability to 'gaming' or malice, and concerned that there is no fundamental relationship between subjective patient experience and objective care quality [Greenhalgh et al 2004, Greenhalgh et al 2008, Ward et al 2008, McCartney 2009]. A pilot review of Patient Opinion in Scotland suggests that some organisations regarded patients' comments as 'unreasonable' [Better Together 2012]. While there is no representative data on the attitudes and behaviour of health professionals to online feedback, and no in-depth analysis of the barriers and facilitators to guide its use in NHS organisations a multi-discliplinary study was underway in 2016 to explore these issues in English hospitals ${ }^{5}$.

While narrative has the potential to be persuasive and memorable, there are some drawbacks. Firstly, in the context of a medical culture of evidence-based medicine, evidence derived from narrative may be resisted as less 'valid' than quantitative studies. Our experience suggests that once people are exposed to narrative its importance becomes obvious, but getting them in the room in the first place may be difficult. We know that engaging doctors in particular in quality improvement remains a challenge (Davies, Powell and Rushmer 2007). Secondly, narrative research is time and resource intensive and requires particular skills to collect and analyse data in a rigorous and theoretically informed way. This is where re-use of

\section{The project, Improving NHS quality using internet ratings and experiences}

(INQUIRE), was funded by the National Institute of Health Research (NIHR) Health Service \&Delivery Research (HS\&DR) scheme (14/04/48). The views expressed are those of the authors and not necessarily those of the NHS, the NIHR or the Department of Health.

https://www.phc.ox.ac.uk/research/health-experiences/researchprojects/improving-nhs-quality-using-internet-ratings-and-experiences-inquire 
existing research, through secondary analysis and through re-use of existing narrative materials, can help. 


\section{References}

Bate P, Robert G (2007). Bringing User Experience to Healthcare Improvement: The Concepts. Methods and Practices of Experience-based Design, Radcliffe Publishing

Berglund B, Lindvall T, Schwela D (1999). Guidelines for community noise: World Health Organisation. Geneva, Switzerland.

Coulter A, Locock L, Ziebland S, Calabrese J. (2014). Collecting data on patient experience is not enough: they must be used to improve care. BMJ: British Medical Journal (Online) 348, g2225

Dal Cin, S, Zanna MP, Fong GT (2004). Narrative persuasion and overcoming resistance. In Knowles ES, Linn JA (eds) Resistance and persuasion, pp. 175-191. Psychology Press, Lawrence Erlbaum Associates, Mahwah, NJ

Darbyshire JL, Greig PR, Vollam S, Young JD, Hinton L (2016). “I Can Remember Sort of Vivid People... but to Me They Were Plasticine." Delusions on the Intensive Care Unit: What Do Patients Think Is Going On? PloS One 11(4), e0153775

Darbyshire JL, Young JD (2013). An investigation of sound levels on intensive care units with reference to the WHO guidelines. Critical Care 17(5), R187

Davies HA, Powell A, Rushmer R (2007). Why don't clinicians engage with quality improvement? Journal of Health Services Research \& Policy 12(3), 129-130

Donetto S, Pierri P, Tsianakas, Robert G (2015). Experience-based co-design and healthcare improvement: Realizing participatory design in the public sector. The Design Journal 18(2), 227-248

Fleming N, VARK: a guide to learning styles, www.vark-learn.com (accessed 2 June 2017)

General Medical Council (2010). The development of treatment and care towards the end of life: good practice in decision making. Available at: http://www.gmcuk.org/Story_of_the_EoL_guidance2.

pdf_32510823.pdf (accessed 18 February 2014)

Green MC, Brock TC (2000). "The role of transportation in the persuasiveness of public narratives. Journal of Personality and Social Psychology 79 (5), 701-721.

Greenhalgh T, Robert G, Macfarlane F, Bate P, Kyriakidou O(2004). Diffusion of innovations in service organizations: systematic review and recommendations. Milbank Quarterly 82(4), 581-629

Greenhalgh T, Russell J, Swinglehurst D (2005). Narrative methods in quality improvement research. Quality and Safety in Health Care 14(6), 443-449

Greenhalgh, T, Stramer K, Bratan T, Byrne E, Mohammad Y, Russell J (2008). Introduction of shared electronic records: multi-site case study using diffusion of innovation theory. BMJ 337, a1786

Heaton, J. (2004). Reworking Qualitative Data, Sage.

Hunt K, France E, Ziebland S, Field K, Wyke S (2009). 'My brain couldn't move from planning a birth to planning a funeral': A qualitative study of parents' experiences of decisions after ending a pregnancy for fetal abnormality." International Journal of Nursing Studies 46(8), 1111-1121

Kelly L, Jenkinson C, Ziebland S (2013). Measuring the effects of online health information for patients: Item generation for an e-health impact questionnaire. Patient Education and Counselling 93(3), 433-438 
The King's Fund (2013). Experience-based co-design toolkit.

https://www.kingsfund.org.uk/projects/ebcd (accessed 2 June 2017)

Kolb AY, Kolb DA (2005). Learning styles and learning spaces: Enhancing experiential learning in higher education. Academy of Management Learning \& Education 4(2), 193-212

Kolb DA, Fry R(1975). Toward an applied theory of experiential learning, in Cooper, C.L. (ed) Theories of Group Processes, pp. 33-58. Wiley, London

Locock L, Robert G, Boaz A, Vougioukalou S, Shuldham C, Fielden J, Ziebland S, Gager M, Tollyfield R, Pearcey J (2014). "Testing accelerated experience-based co-design: a qualitative study of using a national archive of patient experience narrative interviews to promote rapid patient-centred service improvement." Health Services and Delivery Research 2(4)

McCartney M (2009). Will doctor rating sites improve the quality of care? No. BMJ: British Medical Journal (Online) 338

Meisel ZF, Karlawish J (2011). Narrative vs evidence-based medicine-and, not or. JAMA 306(18), 2022-2023

Honey P, Mumford A, (1986) Using your learning styles. 2nd ed. Peter Honey, Maidenhead

Piper D, ledema R, Gray J, Verma R, Holmes L, Manning N (2012). Utilizing experience-based co-design to improve the experience of patients accessing emergency departments in New South Wales public hospitals: an evaluation study. Health Services Management Research 25(4), 162-172

Ryan S, Hislop J, Ziebland S (2016). Do we all agree what "good health care" looks like? Views from those who are "seldom heard" in health research, policy and service improvement. Health Expectations, 1-8

Ward R, Stevens C, Brentnall P, Briddon J (2008). "The attitudes of health care staff to information technology: a comprehensive review of the research literature." Health Information \& Libraries Journal 25(2), 81-97

Ziebland S, Evans J, Toynbee P (2011). Exceptionally good? Positive experiences of NHS care and treatment surprises lymphoma patients: a qualitative interview study. Health Expectations, 14(1), 2128.

Ziebland S, Coulter A, Calabrese JD, Locock L (eds)(2013). Understanding and using health experiences: improving patient care. OUP, Oxford.

Ziebland S, Locock L, Fitzpatrick R, Stokes T, Robert G, O'Flynn N, Bennert K, Ryan S, Thomas V, Martin A (2014). Informing the development of NICE (National Institute for Health and Care Excellence) quality standards through secondary analysis of qualitative narrative interviews on patients' experiences. Southampton (UK): NIHR Journals Library; 2014 Nov. (Health Services and Delivery Research, No. 2.45). 